\title{
FUNDAMENTOS NOEMÁTICOS CAUSATIVOS Y ESTATIVOS ENTRAÑADOS EN LOS ESQUEMAS COGNITIVOS DE DETERMINADOS VERBOS DINÁMICOS'
}

\author{
Esianislao RAMón TRIVES \\ Universidad de Murcia \\ trives@um.es
}

\begin{abstract}
0. Parto de la hipótesis de que el verbo es una categoría lingüística predicativo-relacional que satisface las necesidades del comportamicnto verbal en las más variadas situaciones discursivo-textuales.
\end{abstract}

0.1. El verbo en las lenguas con conjugación verbal lo es en la medida en que el hablante lo considera como pieza verbal modalmente temporalizable y jerárquicamente relacionable con otros segmentos verbales quc protagonizan los diversos roles actanciales intervinientes o propiciados por el proceso significativo fundamental que todo verbo representa. De ahi que considere una mutilación la limitación del llamado SV a lo que, más propiamente, es cl SPred, en la medida en que la capacidad predicativa fundamental del verbo conduce a protagonizar el rol de predicado de los más variados sujctos. Pero así como el rol de predicado cjercido por el verbo no impide que se le asocien otros segmentos que se integran en esa función de predicación, que puede ser ejercida con la presencia única del verbo, de la misma manera no cs lícito, a mi entender, presentar al verbo en la realidad de la operación sintagmático-textual, como pieza lingüístico-relacional ajena o meramente cnfrentada al segmento verbal convocado relacionalmente por el verbo en cuanto $\mathrm{SN}$, pero en la función de contradominio o SSuj que soporta la relación predicativa protagonizada o aportada por el verbo, que es el núcleo dominante dcl escenario sintagmático-textual, en línea con los plantcamientos de L. Tesnière.

0.2.Creo con G. van Houl (1973-1974) que en estos planteamientos no hay sino una simplificación lógica de lo que es la realidad primaria lingüística, sobre todo si tenemos en cuenta que nuestras lenguas privilegian el enfrentamiento entre las llamadas personas gramaticales y los verbos con ellas relacionados. Y digo que es una simplificación lógica porque los verbos como entidades verbales presintagmático-textuales o discursivas no son de ninguna persona, siéndolo de todas y de ninguna, como cualquier sintagma intcgrado en el dominio del sintagma verbal como núcleo verbal dominante no es ni deja de ser ajeno

1 Este trabajo se inscribe dentro del Proyecto BFF2002-02442, «Verbos de estado en español. Modelos cognitivos y procesos de estructuración categorial», Comisión Interministerial de Ciencia y Tccnología. 
al verbo, no ya porque podamos tener verbos autosuficientes cuyo núcleo predicativo se satisfaga a sí mismo, sino porque, en la operación sintagmático-textual o discursiva, cualquier verbo, por muy transitivo que pueda ser, ticne la virtualidad de protagonizar el rol de predicado por sí mismo.

0.3. Pero es que la relación SUJ $\leftarrow$ PRED, siendo un aspecto importante de la operación verbal, no es la única $y$, sobre todo, no es la primera relación en la que se sustancia la complejidad relacional de segmentos verbales de gran capacidad relacional como es el verbo, que es en cierto modo una característica que conviene a los más variados sintagmas o segmentos verbales, sea cual sea el lugar de contradominio o dominio de la operación sintagmático-textual protagonizada por un verbo dentro del comportamiento verbal. El verbo como entidad significalivo-relacional compleja no sc materializa como significante pleno sino en la medida en que materializa una de sus múltiples posibilidades paradigmático-morfológicas, que son y se comportan como significante verbal concreto en la medida en que se oponen a las distintas posibilidades morfológicas en su conjunto. Lo cual entraña no ya que como cualquier unidad significativo-verbal sea identificada por el juego desempeñado en el paradigma léxico-significativo que le hace ser significante concrcto, sino también en el marco del rico paradigma morfológico-flexional en el que el verbo articula las posibilidades predicativo-relacionales fundamentales en las lenguas morfológicamente categorizadas como cl español. La mera transformación de construcciones verbales como [Doré ilustró El Quijote], [Clemencín comentó EI Quijote], etc., en sus equivalentes nominales como [Las ilustraciones del Quijote de Doré], [Los comentarios del Quijote de Clemencín], [Las ilustraciones de Doré], [Las ilustraciones del Quijote], [Los comentarios de Clemencín], [Los comentarios del Quijote], pueden evidenciar la complejidad relacional subjetivo-objetiva protagonizada por los verbos.

0.4. La predicación enunciativa orienta la disposición o despliegue sintagmático en un sentido subjetivo u objetivo en función de los parámetros que se quieren focalizar o tematizar, pero es un segundo paso, por encima del hecho primario de que el auténtico SV no es el que se suele indicar en los diagramas arbóreos a la derccha del llamado SN, siendo así que cl autćntico SV no es ni más ni menos que el conjunto de segmentos significativos que en un enunciado real o virtual se presentan dominados por un verbo, y esto en sentido especifico, en lo que el lexema verbal reclama como lexema individual especifico dentro de un paradigma lexemático, que son los candidatos ortonímicos o metafóricos en la complementación especifica o caracterización del núcleo verbal dominante, y en sentido genérico, on lo que el paradigma verbal al que pertencce el verbo tolera como clase de paradigmas lexemático-verbales, donde, como es obvio, las circunstancias espacio-temporales y modales, entre otras, son candidatos de máxima frecuencia en la complementación genérica o identificación de la clase del núcleo dominante, y a este propósito, como se vcrá más adelante acerca de los enunciados identificados infra como b., d., etc., habrá que tener en cuenta que el múcleo dominante respecto del cual otros parámetros significativos pueden presentar una relación morfosemántica debe ser identificado en los estadios subyacentes entrañados en el cstadio final o enunciado resultante. 
0.5. El auténtico sintagma verbal presenta dos capas de dominancia, una específica y otra genérica, más allá de lo que resulte ser el enunciado concreto, producto del trabajo predicativo-enunciativo del hablante con las focalizaciones, tematizaciones, suposiciones, presuposiciones e implicaturas que el hablante decida y protagonice en función de las exigencias de su opcración verbal. Entonces es cuando determinados sintagmas actúan de sujeto y otro/s de predicado, pero subyace a cualquiera otra consideración la arriba señalada con respecto al protagonismo del verbo en relación con todos sus complementos, cn el sentido de L. Tesnière (1959), según el cual el sintagma llamado sujeto básicamente es un complemento actancial más, $y$, como hemos señalado, privilegiado en nuestras lenguas de conjugación subjetiva o subjetivo-objetiva, como el español. El esquema subyacente a cualquier SV vendría a ser el siguiente:

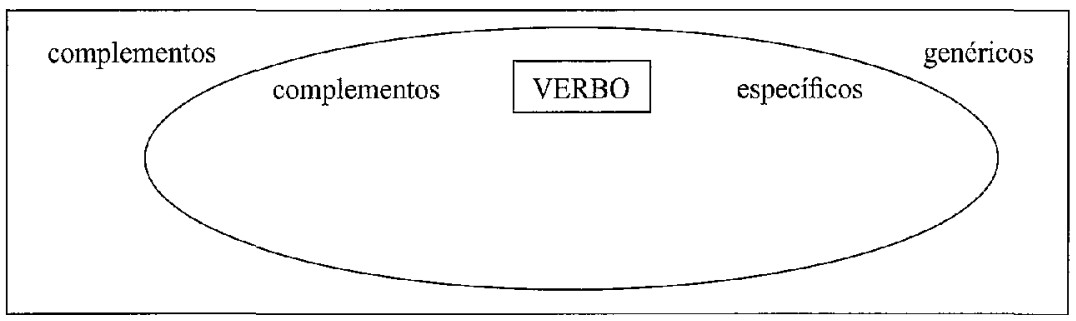

1.Gran parte de los verbos dinámicos como abrir, cerrar, subir, bajar; llevar, traer, poner; quitar, etc. presentan procesos complejos no sólo «ablativo-adlativos», sino estativo-ablativos y estativo-resultativos o ablativos. Ante frases como

a. Juan puso la fruta en el almacén en tres horas

que es una construcción con perspectiva ablativo-adlativa, cuyo marco temporal afecta al proceso ablativo-adlativo, nos encontramos con frases emparentadas formalmente como

\section{b. Juan puso la fruta en el almacén tres horas}

que es una construcción ablativo-adlativa estativo-resultativa, cuyo marco temporal afecta al resultado del proceso ablativo-adlativo.

En a., la temporalización representada por el sintagma [en tres horas] incide en el proceso transformativo ablativo-adlativo representado por [Puso la fruta en el almacén].

Esquemáticamente, podemos representar dichas características de la siguiente forma:

[[Juan puso la fruta en el almacćn] en tres horas]ฏ[|Juan almacenó la fruta] en tres horas]]

lo que viene a ser lo mismo que el modelo de inclusión siguiente: 


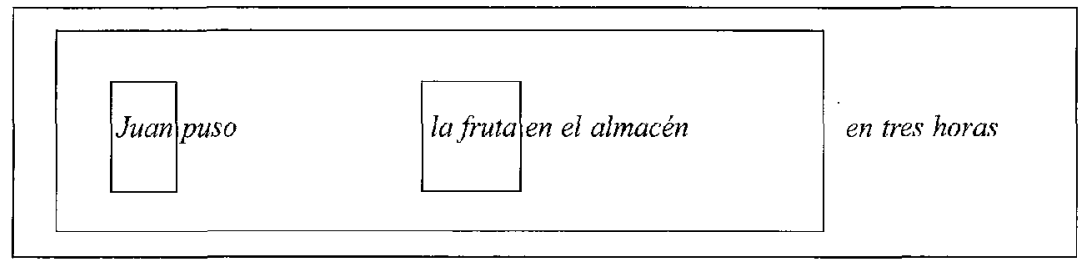

[\{Juan $\rightarrow$ la fruta $\subset$ almacén\} $\subset\{$ tres horas\}], donde se observa que dado Juan y su dinámica actividad ablativo-adlativa, se desencadena un proceso cognitivo complejo de inclusión de la fruta con respecto al almacén, y todo ese proceso se desarrolla en el marco temporal de tres horas. Los relatores tanto verbales como preposicionales, pero sobre todo los verbales, son vectores cognitivos por donde circula el proceso mental de puesta en relación de unos bloques significativos con respecto a otros. Son ellos los responsables de la actividad intelectiva o energía mental que se dinamiza a la hora de poner en relación unos bloques significativos respecto de otros.

Los significantes nominales son como los bloques relativamente inamovibles primarios por los que circula la energia intelectiva representada muy especialmente por verbos y preposiciones, que pese a que son en la medida en que se configuran morfológicamente, no esconden sino que propician la dinamización del entramado intelectivo-relacional de la operación verbal en su integridad, que como todo lo holonímicamente configurado no se deja atrapar por ninguno de sus estadios procesales, ni siquiera el último, que lo es de un largo proceso para el hablante responsable, y cs cl estadio primero del hablante responsable de su intelección e interpretación, cuyo proceso final se ensaya con cualquier enunciado concreto en una suerte de réplica $\sin$ fin. Por eso los relatores, tanto verbales como preposicionales, se dejan materializar mediante significantes analíticos, reflejo de diversos estadios previos, o sintéticos, en cuanto integradores del conjunto de elementos convocados por los más diversos enunciados de diverso alcance.

En los enunciados arriba propuestos, tanto poner como en se dejan analizar en los estadios que reflejan los distintos momentos del proceso de puesta en relación de unos bloques significativos respecto de otros, en nuestro caso Juan, fruta, almacén, en primera instancia, y tres horas, en última instancia, a la hora de enmarcar temporalmente el proceso. A la hora de dar cuenta de los distintos estadios del proceso expresivo-verbal de cualquier enunciado, se puede observar cómo las distintas variaciones o estadios enunciativos posibles no se dan sobre los bloques significativos primarios o nominales, sino que sc propician fundamentalmente según los distintos momentos de la puesta en relación de unos elementos nominales respecto dc otros, dando cuenta de los momentos álgidos por los que circulan como corriente o energía intelectiva las distintas resultantes de puesta en relación de unos elementos con respecto a otros:

a.1.Juan hizo que la fruta que estaba fuera del almacén pasara a estar dentro, y todo eso lo hizo en el marco temporal de tres horas;

a.2.Juan extrajo la fruta del lugar donde se encontraba y la introdujo en el almacén durante un tiempo de tres horas.

a.3.Juan fue el responsable de que la fruta que estaba en un sitio distinto del almacén pasase al almacén en el ámbito de tres horas. 


\section{a.n. $\{\{$ Juan $\rightarrow\{$ fruta $\subset$ almacén $\}\} \subset$ tres horas $\}\}$}

Por lo cual, cn cl modclo actancial de Klaus Heger (1976:102 y ss.), el enunciado a. vendría a representarse de la siguiente forma:

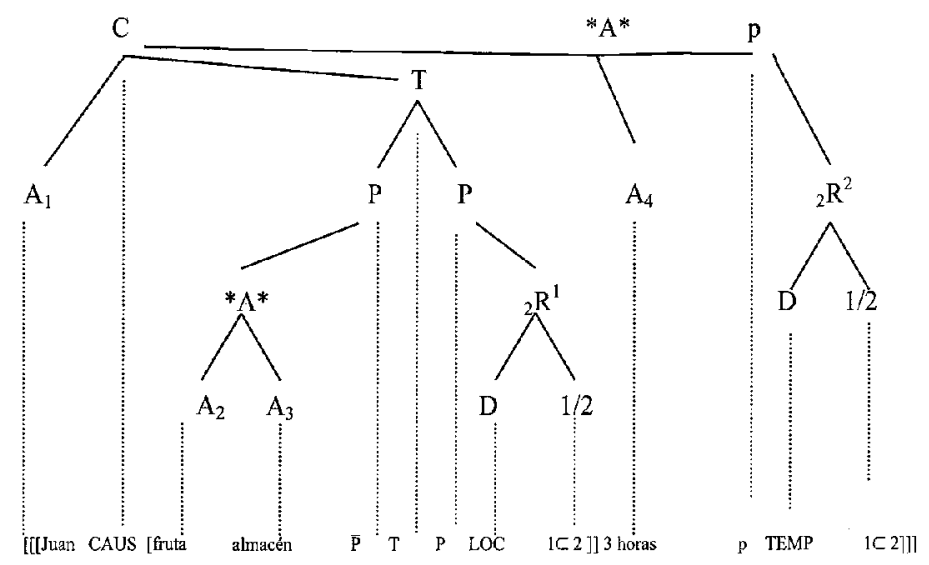

El tiempo (TEMP) empleado por Juan en su aclividad de almacenamiento de la fruta fue equivalente a tres horas; por eso se vincula cognitivamente con Juan como responsable (CAUS) del proccso ablativo-adlativo.

En b.,la temporalización representada por el sintagma [tres horas] incide en el resultado del proceso transformativo ablativo-adlativo represcntado por [Juan puso la fruta en el almacén].

Esquemáticamente, podemos representar dichas características de la siguiente forma:

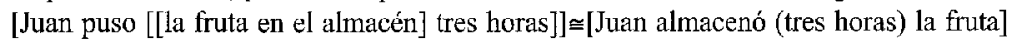

lo que viene a ser lo mismo que el modelo de inclusión siguiente:

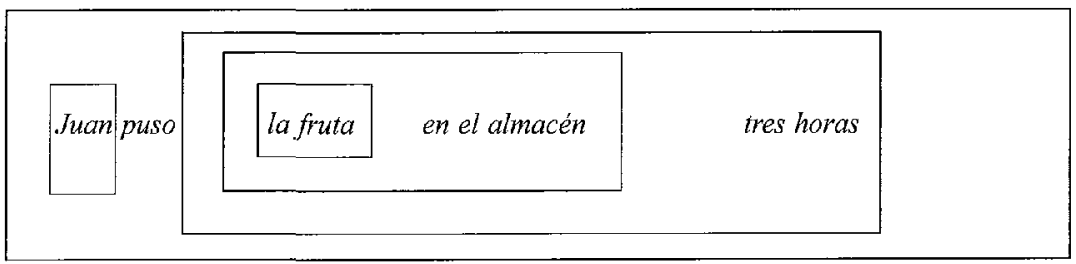

donde el sintagma tres horas afecta al resultado estativo como característica de marco que circunscribe el estado de almacenamiento de la fruta, que es el resultado de la acción eficiente de Juan, y no como marco de la actividad o dinámica ablativo-adlativa reflejada en a.

Por lo cual, en el modelo actancial de Klaus Heger (1976:102 y ss.), el enunciado b. vendria a representarse de la siguiente forma: 


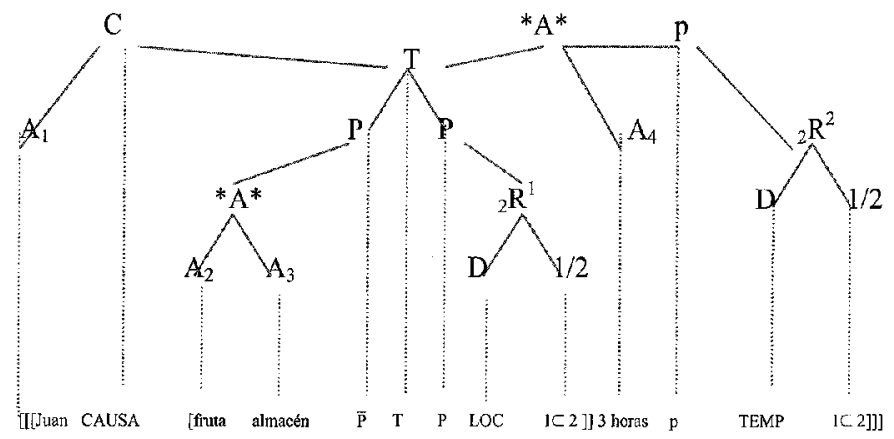

El marco temporal (TEMP) cmpleado por Juan en su actividad de almacenamiento de la fruta no se menciona en el enunciado así esquematizado cognitivamente; en cambio, sí se menciona dicha temporalidad (TEMP), marco, tres horas, que afecta al resultado estativo como característica de la situación de almacenamiento de la fruta. Por eso se vincula cognitivamente con la fruta en el almacén (LOC) como resultado durativo del proceso ablativo-adlativo.

La analogía con otros sintagmas puede servir de argumento convergente con lo que venimos diciendo. Se trata de hacer ver cómo las auténticas relaciones actualizadas con respecto a un verbo no son sino virtuales, es decir nunca son reales sino en un enunciado real, más allá de la indiscutible realidad virtual, Piénsese en enunciados del tipo siguiente:

\section{c. Juan puso la uva con la gráa en el almacén vs \\ d. Juan puso la uva con la mies en el almacén}

donde el sintagma con la grúa en c. afecta a la dinámica ablativo-adlativa propia de la actividad de Juan, poner, mientras que en d. el sintagma con la mies afecta a la situación comitativa de la fruta, cuya situación resultativa ablativo-adlativa comparte con la mies.

Este distinto resultado en la incidencia de los sintagmas configurados formalmente de modo idéntico (con la gria/con la mies) procede de la sintagmática integrada de las unidades significativas que constituyen el enunciado en cada caso.

2. A pari, los esquemas actanciales noemático-cognitivos que subyaccn a los enunciados c. y d. se pueden visualizar de la siguiente forma: 
c. Juan puso la fruta con la grüa en el almacén:

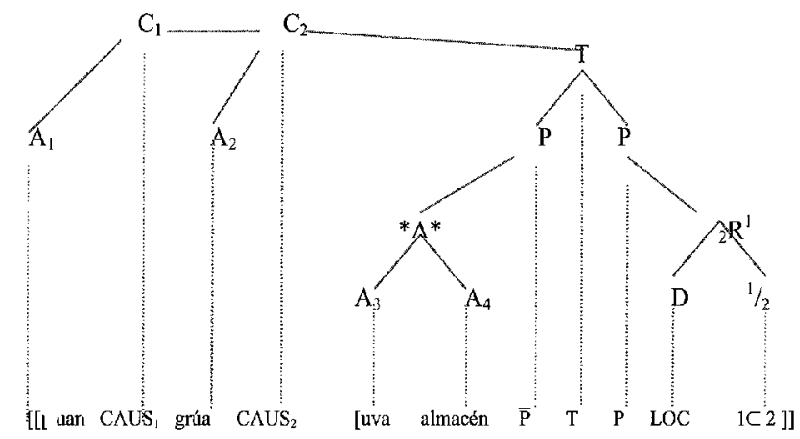

Se trata de dinamizar el instrumento o causa segunda, concausa, grúa, por parte de la causa desencadenante o primera, Juan, en una suerte de concatenación actancial que se vuelca sobre el proceso de almacenamiento de la uva, que, obviamente, es el resultado del dinamismo ejercitado por los actantes, que, siendo externos al proceso ablativo-adlativo desarrollado o soportado por la uva con respecto al almacén, son los responsables o desencadenantes del desplazamiento de la uva, que ubicada fuera del almacén, pasa a situarse dentro del almacén. Resulta evidenciable que para dar cuenta del sentido integrado en los diversos enunciados no sólo hemos de actuar desde los datos emanantes de cada uno de los segmentos integrantes, desde una perspectiva computacional o meronímica, sino que, además, es preciso entender el proceso en su conjunto con el fin de integrar, desde una perspectiva holonímica, el lugar utópico configurador o integrador de todos los componentes y de los diversos estadios desencadenados por el proceso enunciativo en su integridad.

d. Juan puso la uva con la mies en el almacén:

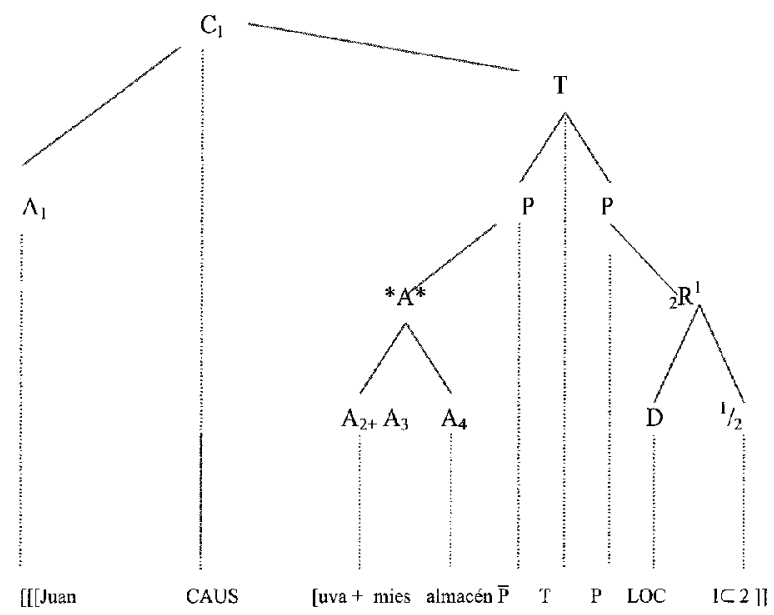


La relación sumatoria de mies con respecto a uva, en contraste con la relación coopcradora reflejada en e., no surge desde los sintagmas elementales, desde una mera perspectiva meronímica, sino desde su integración en un proceso cnunciativo en el que se machihembran holísticamente todos los componentes. En efecto, la virtualidad de un esquema sintagmático como el reflejado por /con + SN/ no puede integrarse a ciegas, al margen de su energía simbólico-significativa, sino desde su respectividad con la de los otros sintagmas elementales. $Y$, justamente, desde su azarosa y dinámica interrelación surge la necesaria integración ulópica de su configuración holonímica, donde se machihembra mies con uva, y se deja a Juan la responsabilidad desencadenante del proceso ablativo-adlativo, en virtud del cual tanto mies como uva salen de su ubicación particular para alojarse en un espacio compartido, almacén.

3. Análogamente, abrir y su complementario cerrar pueden ser considerados como esquemas verbalcs resultantes de un proceso estativo ablativo-adlativo de distinto signo, donde los dos estados, el cerrado y el abierto, se integran en sentido complementario.

La energía intelectivo-relacional o esquema cognitivo del proceso estativo subyacente a este tipo de verbos dinámicos, desde una perspectiva holonímica, no puede ser integrada sino utópicamente, incapaces de detener el proceso en ninguno de sus estadios, que no agotan la complejidad procesal cognitiva de la que son parte integrante, de acuerdo con una legítima y necesaria, aunque insuficiente, perspectiva meronímico-racional, que reclama exigencialmente, para su cabal entendimiento integral, la dinamización de la necesaria perspectiva holonímico-intelectiva complementaria.

Piénsese en los planteamientos analítico-integradores siguicntes:

\section{e. Iuan abrió/cerró el almacén con dos llaves}

vs

f. Juan abrió/cerró el almacén dos horas

is

g. Juan abrio/cerró el almacén tres veces

vs

h. Juan dejó el almacén abierto/cerrado dos horas

vs

\section{i. Juan mantuvo abierto/cerrado el almacén dos horas}

Todos estos enunciados de e. a i. toleran análogas aproximaciones cognitivo-intepretativas a las realizadas con respecto a los enunciados propuestos de a. a d. A todos estos enunciados subyace análogo esquema noemático-cognitivo, que podemos reflejar en los siguicntes términos: 


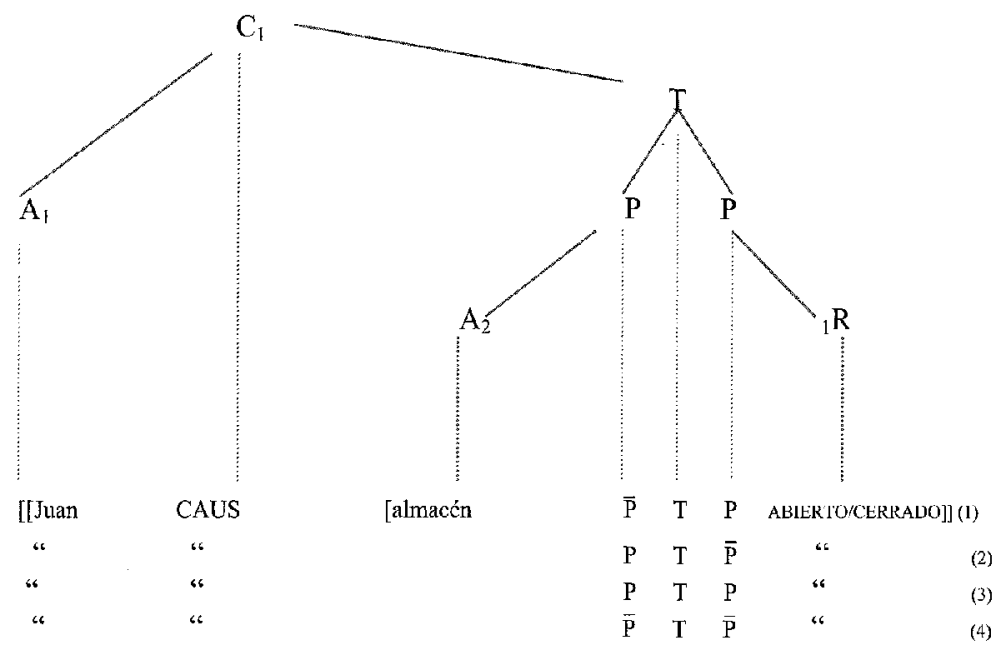

(1) Juan motivó que el almacén que no estaba abierto/cerrado se abriera/cerrara

(2) Juan motivó que el almacén que estaba abierto/cerrado se cerraralabriera

(3) Juan motivó que el almacén que estaba abierto/cerrado siguiera abierto/cerrado

(4) Juan motivó que el almacén que estaba cerrado/abierto siguiera cerrado/abierto

En cualquiera de las situaciones, nos encontramos con un estadio de partida del proceso ABIERTO/CERRADO que, obviamente, es estativo-transformativo, y sc cncamina al final del proceso hacia un estadio de llegada o término CERRADO/ABIERTO que es transformativo-estativo. Más allá de estas equivalencias de base, se producen diferencias de un enunciado respecto de otros. Así, en

e. Se reproduce el esquema señalado en (1) con el añadido de un funtor causal secundario que con el funtor causal primario desencadenan el proceso estativo ablativo-adlativo según el modelo noemático-actancial propuesto para los enunciados a. y c.;

f. se reproduce el esquema señalado cn (1) con el añadido de un funtor temporal que afecta al proceso estativo ablativo-adlativo, de modo similar a lo que se refleja en el esquema noemático-actuancial propuesto para el enunciado b.;

g. se reproduce el esquema señalado en (1) con el añadido de un funtor temporal iterativo que afecta al proceso dinámico en su integridad en el modo en que se representa en el modelo noemático-actancial propuesto para los enunciados a. y c.;

h. se reproduce el esquema señalado en (3) y (4), sin excluir la recursividad temporal dol proccso estativo, en el sentido de que dejar no excluye que se actúe sobre el estadio de partida y se modifique, en un proceso transformativo-estativo, y que, ulteriormente, se mantenga el estadio de llcgada o término del proceso en una sucrtc de mantenimiento del statu quo estativo alcanzado;

i. se reproduce el esquema señalado en (3) y (4), que, a diferencia de lo comentado con respecto a h., temporaliza la situación estativa según tiempos sucesivos sin modificación del statu quo estativo inicial ABIERTO/CERRADO. 
4. La facilidad con que en el comportamiento de determinados verbos dinámicos afloran distintos estadios de los complejos esquemas cognitivo-procesales puede ser otra prueba del componente estativo inherente a los esquemas noemático-cognitivos integrados en los verbos dinámicos, en línea con lo que planteamos en este momento. El llamado predicativo, observable en muchas construcciones sintagmáticas de estos verbos, envuelve idea de predicado estativo, precisamente.

Piénsese en los enunciados propiciados por el verbo ANDAR, CAMINAR, IR, ENCONTRAR, etc., cuya variada sintagmática no hace sino aflorar los distintos componentes de la compleja esquemática cognitivo-proyectiva reflejada por los verbos dinámicos aquí presentados. El verbo IR, por ejemplo, como resultado morfosemántico de sucesivos estadios estativos, presenta una variada sintagmática, en cuyos vaivenes se refleja el proceso noemático-estativo subyacente, que hacen aflorar, como venimos señalando, los componentes sintagmáticos predicativo-adjetivales y adverbiales, preposicionales y no preposicionales, etc., sobre los que domina en los más variados enunciados, según se refleja en la siguiente serie no cerrada de posibilidades sintagmáticas:

$$
\begin{aligned}
& I R+\text { como un }+\mathrm{SAdj} \\
& \mathrm{IR}+\mathrm{SAdv} \\
& \mathrm{IR}+0 \cong \mathrm{Marchar} \\
& \mathrm{IR}+\text { ante/bajo/cabe/so }+\mathrm{SN} \\
& \mathrm{IR}+\mathrm{a}+\mathrm{SN} \cong \mathrm{IR} \text { a estar en }+\mathrm{SN} \\
& \mathrm{IR}+\text { sin }+\mathrm{N} \\
& \mathrm{IR}+\text { para }+\mathrm{SN} \cong \mathrm{Se} \text { va a convertir en }+\mathrm{N} \cong \mathrm{Va} \text { a ser }+\mathrm{N} \\
& \mathrm{IR}+\text { segun }+\mathrm{SN} \\
& \mathrm{IR}+\text { de }+\mathrm{N} \cong \text { Hacerse pasar por } \mathrm{N} / \text { Haccrsc pasar por } \mathrm{scr}+\mathrm{N} \\
& \mathrm{IR}+\text { por }+\mathrm{N} \cong \text { Fue a causa de }+\mathrm{N} / \text { Fue para conseguir }+\mathrm{N} \\
& \mathrm{IR}+\text { tras }+\mathrm{SN} \cong \text { Tratar de hacerse con }+\mathrm{SN} \\
& \mathrm{IR}+\text { sobre }+\mathrm{SN} \cong \text { Estar sobre }+\mathrm{SN} \\
& \mathrm{IR}+\text { entre }+\mathrm{N} \text { (lenguas) } \cong \text { Estar }+ \text { adj (difamado) } \\
& \mathrm{IR}+\text { desde }+\mathrm{SN} \cong \text { Estar }+ \text { desde }+\mathrm{SN} \\
& \mathrm{IR}+\text { ppdo. } \cong \mathrm{Estar}+\text { ppdo. }
\end{aligned}
$$

Como ya señalamos en otro lugar, el sintagma no hace sino revelar el paradigma subyacente. En cfecto, los verbos dinámicos transformativos de situaciones, actitudes, etc., como se ha podido ver a lo largo de esta reflexión, integran en su estructura noemático-sintagmática subyacente características propias de los verbos atributivos o estativos en diversos estadios de su proceso enunciativo, que son aflorados por los sintagmas circunstantes actualizados en los enunciados concretos en forma de predicativos, complementos de lugar, tiempo, modo, etc.

\section{REFERENCIAS BIBLIOGRÁFICAS:}

Abeillé, A. (2002): Une grammaire électronique du français, CNRS Éditions, París.

Heger, K. (1976): Monem, Wort, Satz und Text, Tübingen.

IIelbig, G. (1971): «Theoretische und praktische Aspekte eines Valenzmodelle», en Gerhard Helbig (IIrsg.), Beiträge zur Valenztheorie, Janua Linguarum, Series minor 115, Mouton, 31-49.

Hofstadter, D. (2000 (1985)): Gödel, Escher; Bach. Les Brins d'une Guirlande Eternelle, Dunod, París. 
Houdé, O. (2003 (1998)): Vocabulaire de sciences cognizives. Neuroscience, psychologie, intelligence artificielle, linguistique et pohilosophie, QUADRIGUE / PUF, París.

van Hout. G. (1974); Franc Math. Essai pédagogique sur les structures grammaticales du français moderne, III, La proposition, Didier, Paris.

Ramón Trives, E. (1979): Aspectos de semántica lingüistico-textual, Istmo, Madrid.

Tesnière, L. (1966 (1959)): Éléments de syntaxe structurale, Klincksieck, París. 